\title{
As ideias de Brasil: fundamentos de um debate crítico entre Roberto Schwarz e Silviano Santiago ${ }^{1}$
}

Fabiana Carneiro da Silva

\section{O que emoldura as ideias: a estruturação de um campo}

Durante um grande período a literatura, bem como a crítica literária, constituíram no Brasil um espaço privilegiado para a reflexão sobre a nação. A partir da década de 30, iniciou-se um movimento de composição e institucionalização de outras disciplinas, como a sociologia, que criaram um espaço de competição e deslocaram a centralidade desse debate. A crítica literária sofreu um processo de especialização, atrelado e legitimado pelo vínculo com a universidade. Neste sentido, ganhou maiores contornos um campo literário relativamente autônomo, no qual atuam uma série de sujeitos, desde diversos posicionamentos. ${ }^{2}$

As ações de institucionalização dos estudos literários tiveram como expoentes Afrânio Coutinho, sobretudo no Rio de Janeiro e Bahia, e Antonio Candido, em São Paulo, constituindo essa área a partir de objetos e métodos que participavam de um projeto de construção da identidade nacional. Nessa direção, Luiz Costa Lima define três eixos predominantes na atividade crítica-literária brasileira do período, a saber: literatura nacional, especificidade da linguagem literária e relação da linguagem literária com a sociedade. ${ }^{3}$ De acordo com ele, notoriamente Candido investiu na formação de um sistema literário contínuo, ininterrupto e linear como algo gradativo e orgânico, ressaltando as produções que favorecessem a coesão nacional.

Candido teve suas proposições legitimadas a partir do vínculo institucional com a Universidade de São Paulo, que, por sua vez, já possuía um discurso de saber validado pelas

1 Uma versão mais desenvolvida desse texto pode ser acessada em minha dissertação de mestrado (ainda não publicada): Tensões do pensamento nacional no diálogo crítico entre Roberto Schwarz e Silviano Santiago, disponível em: http://www.teses.usp.br/teses/disponiveis/8/8151/tde-13122012-103821/pt-br.php.

2 A ideia de campo, formulada, a partir da sociologia religiosa de Weber, por Pierre Bourdieu, faz referência a um espaço intermediário entre uma determinada área e seu contexto social, isto é, a um espaço que obedece leis específicas e que constitui uma forma específica de capital. Neste espaço identificamos, pois, uma margem de autonomia, mas, por ser comunicante com o exterior, também uma margem de heteronomia, ou seja, nele não deixam de se expressar aspectos políticos, econômicos, relações de força, etc. BOURDIEU, Pierre. As regras da arte: gênese e estrutura do campo literário. São Paulo: Companhia das letras, 1996.

3 LIMA, Luiz Costa. "Concepção de História Literária na "Formação". In: Dentro do texto, dentro da vida: Ensaios sobre Antonio Candido. [D’ trincas, Maria Ângela e Scarabotolo, Eloísa Faria (orgs)]. São Paulo: Cia das Letras, 1992; p.153-169.

RASILIANA- Journal for Brazilian Studies. Vol. 6, n.1 (December 2017). ISSN 2245-4373. 
gerações anteriores - constituídas por intelectuais fundadores de um discurso de interpretação da realidade brasileira, como Sérgio Buarque de Holanda, Gilberto Freyre e Celso Furtado. Esses pensadores, como nos informa Ana Cecilia Olmos em sua tese de doutorado, em parte compartilhavam a função atribuída à Faculdade de Filosofia, Letras e Ciências da USP, criada na década de 30, que era a de "llevar adelante una reflexión sobre la nación que, bajo el prisma del 'interés general' definiese una determinada consciencia social". Ao mesmo tempo, tiveram que lidar com o fato de a USP ser uma universidade cuja história esteve - e está - vinculada às classes dominantes paulistas, em função de seu projeto de formar novas classes dirigentes para o país. ${ }^{4}$

A formação da crítica a partir desses elementos contraditórios consolidou-se como o núcleo problemático do pensamento nacional. Assumindo como necessário o gesto de análise sobre os desdobramentos e sobre o estado atual, leia-se século XXI, desse pensamento e das questões que ele suscita, propomos uma reflexão ancorada na comparação de dois significativos ensaios de autores que desenvolveram leituras críticas contundentes e ocupam posições antagônicas nas disposições do campo literário brasileiro; são eles: Silviano Santiago e Roberto Schwarz.

Sendo assim, neste artigo, realizamos uma aproximação do projeto desses críticos, a fim de estabelecermos as relações entre seus critérios de valoração estética e suas avaliações de aspectos da cultura brasileira, dando ênfase ao tópico da subordinação econômica versus (in)dependência cultural e sua relação com o nacionalismo. Em outros termos, conceberemos tais autores como intelectuais que, desde a teoria literária, utilizam-se de instrumentos de avaliação da literatura para efetuar - sempre de forma vinculada a uma dada conjuntura sociopolítica - interpretações sobre as dinâmicas da cultura nacional. A fim de realizar tal comparação e, com isso, compreender qual é a função e o peso, para a crítica contemporânea, das ideias propostas por eles, precisaremos localizar e reconstituir um diálogo que ocorre de modo explícito em seus textos, mas que permanece pouco visibilizado. Do mesmo modo, será imperativo apreender, para além das proposições discutidas, os elementos que emolduram o debate e são responsáveis pelos lugares que Schwarz e Santiago ocupam no campo, bem como, pelas estratégias de autolegitimação e conquista de capital simbólico utilizadas por eles e por aqueles que dão continuidade aos seus projetos.

4 OLMOS, Ana Cecilia Arias. Revistas Culturales de la transición: prácticas políticas y estrategias de intervención cultural - una lectura comparada de Punto de vista y Novos Estudos Cebrap. São Paulo: FFLCH-USP, 2000, p.57-71.

RRASILIANA- Journal for Brazilian Studies. Vol. 6, n.1 (December 2017). ISSN 2245-4373. 
Schwarz insere-se na chamada "tradição nacional" ao elaborar e dar novos rumos aos estudos desenvolvidos por Candido, e, em alguma medida, consolidar o projeto desse crítico, sobretudo em seu aspecto sociológico, isto é, a tentativa de propor uma leitura da sociedade brasileira via literatura. Utilizando-se de uma chave de leitura que mobiliza parte do repertório crítico da Escola de Frankfurt, associado a um tradicional discurso de interpretação sociológica do Brasil, Schwarz adquire notoriedade ao formular certo impasse constituinte de nossa cultura e apreensível em certas obras literárias.

Já Silviano Santiago, que teve como mentor intelectual Alexandre Eulálio, é um crítico que opera um desvio em relação ao mencionado tradicional discurso constituinte das interpretações da sociedade brasileira. Ele incorpora à sua orientação formalista - que qualifica como "formação de vanguarda" - importantes proposições da Desconstrução, em especial aquelas formuladas por Jacques Derrida. Formado pela Universidade Federal de Minas Gerais, Santiago atuou como docente por muito tempo na França, Canadá, Estados Unidos e Rio de Janeiro (na Universidade Federal Fluminense) e escreve, portanto, desde um outro espaço e de um outro vínculo institucional. Contudo, conforme veremos, também compõe suas proposições teóricas a investigação do que se entende como contexto nacional e, nesse sentido, confirma, abrindo margens para sua problematização, o compromisso do intelectual brasileiro com o social.

\section{A contraposição produtiva: "As ideias fora do lugar" e "O entre-lugar do discurso latino- americano"}

A diferença entre as abordagens de Roberto Schwarz e Silviano Santiago implica um empenho particular de análise que tem a tentativa de constituição de um espaço público para o debate entre marxismo e desconstrução ${ }^{5}$ como esforço subjacente ao desenvolvimento deste artigo. Nessa direção, é imperativa a leitura do ensaio "As ideias fora do lugar", de 1973, que tornou-se amplamente difundido e discutido no campo das letras brasileiras mobilizado nessa reflexão. Por se tratar de um ensaio denso e muita vez mal compreendido, iniciaremos com a retomada de suas proposições principais, as quais desdobraremos adiante.

A reflexão schwarziana tem como referencial, neste ensaio, o período do Segundo

5 Comentando a ausência de recepção do texto Espectros de Marx de Derrida, no Brasil, Fábio Durão escreve: "Isso não espanta, pois está de acordo com a natureza do debate sobre desconstrução e marxismo por aqui - um debate inexistente. 'Desconstrucionistas' não têm o menor interesse em ler Marx; 'Marxistas' têm ojeriza pelo nome de Derrida". DURÃO, Fabio Akcelrud. "Marx e seus Espectros: Reconstituindo um Debate". In: Desconstruções e contextos nacionais.[Santos, Alcides Cardoso dos, Durão, Fábio Akcelurd, Silva, Maria das Graças G. Villa da (orgs.]. Rio de Janeiro: 7 letras, 2006; p. 224.

RASILIANA- Journal for Brazilian Studies. Vol. 6, n.1 (December 2017). ISSN 2245-4373. 
Reinado brasileiro. Por meio de um complexo movimento analítico-argumentativo, o crítico demonstra a impropriedade da vida ideológica no Brasil como uma constante que perpassa todas as esferas sociais - mas adquire especial configuração em nossa prosa literária, sobretudo na obra de Machado de Assis. Nesta direção, o ensaio apresenta uma hipótese de compreensão da dinâmica da vida cultural do país; para isso Schwarz, à luz da teoria marxista, parte da apreensão de uma totalidade cuja lógica é a do capitalismo e avança na busca do nexo mediador das condições de existência do Brasil dentro dessa ordem.

O principal elemento que salta às vistas do crítico é a presença da escravidão que, associada ao latifúndio, forma a base das relações produtivas nacionais do período. Sendo essa coadunação concebida como nossa realidade material, a relação que ela estabelece com o ideário liberal, cujo núcleo está preenchido com os conceitos de igualdade, liberdade individual e, logo, de trabalho livre, é desvelada como paradoxal. Desse modo, segundo o crítico, o conjunto de ideias que na Europa correspondiam às aparências - e que efetivamente agiam como ideologia, à medida que mascaravam a exploração e as relações desiguais entre os sujeitos -, no Brasil constituíam uma ideologia de segundo grau, ou seja, nem sequer às aparências correspondiam.

Para que tal incongruência estrutural, entre as ideias e a realidade material, se mantivesse, era necessária a cumplicidade dos agentes sociais, que não podiam deixar de notá-la. Essa cumplicidade, e aí nos é apresentado o nexo que constitui a vida ideológica dentro de tal ordem, era, segundo Schwarz, assegurada por uma "lógica do favor". O favor, portanto, nas palavras do crítico, constituía uma mediação que disfarçava e deslocava o foco da violência e impropriedade da nossa esfera produtiva, ao por em prática a "dependência da pessoa, a exceção à regra, a cultura interessada, [a] remuneração e [os] serviços pessoais" ${ }^{\prime \prime}$, tudo contrário aos valores burgueses. Tal mecanismo, instaurado sobretudo nas relações entre proprietários e homens livres, garantia a sobrevivência e reprodução destes, dos quais fazia parte a grande parcela dos homens dedicados à atividade intelectual da época.

Em alguma medida, dada característica brasileira impedia uma racionalização integral, ou seja, a efetivação do que se entende como a racionalidade moderna. ${ }^{7}$ Sem

6 SCHWARZ, Roberto. "As idéias fora do lugar". In: Novos Estudos CEBRAP, n. 3, 1973. A edição que utilizo está no livro: Ao vencedor as batatas: Forma literária e processo social nos inícios do romance brasileiro. São Paulo: Duas Cidades, Ed. 34, 2000; p. 17.

7 Esse dado abrirá margens para os discursos da "modernização incompleta", que vislumbraram no desenvolvimentismo uma possibilidade de inserção integral do Brasil na modernidade. Essa mesma noção de incompletude de nossa racionalização dentro dos paradigmas ocidentais permitirá ao crítico José Miguel Wisnik explorar como potencial positivo os elementos não racionalizados de nossa cultura, tais como o futebol, a dança, o jogo,a música e a gestualidade. WISNIK, 
embargo, esse estado de coisas, como avança Schwarz em sua tese, era resultante direto da própria expansão burguesa, capitalista, e, como tal, sua condição de existência, seu resíduo suplementar. Logo, as ideias do tempo eram enviesadas e a sensação de desconcerto e dualismo predominante, mas, ainda que "fora de centro em relação às exigências que elas mesmas propunham", essas ideias eram "reconhecivelmente nossas, nessa mesma qualidade". 8

Sendo assim, o estatuto de (ex)colônia implicava tal desajuste e por isso, como enfatiza Schwarz, pouco ajudava a reiteração da falsidade das ideias liberais no Brasili , já que elas tinham seu momento de verdade e necessidade (foram importantes, por exemplo, para o abolicionismo). Para ele, o mais interessante e produtivo criticamente seria acompanhar o movimento dessas noções e seus desdobramentos no país. Se por um lado, essa condição "decerto baixava o cotidiano da vida ideológica e diminuía as chances de reflexão"10, por outro, desmascarava o falso universalismo da ideologia europeia e nos conferia o potencial crítico de ver o "universal" como localizado e relativo - o que, de algum modo, poderia ser lido como um privilégio epistemológico. Ao ler ensaios posteriores de Schwarz, notamos que em suas novas avaliações os desdobramentos desses mecanismos expostos parecem ter atravessado os séculos e, ainda hoje, no século XXI, estruturariam e determinariam nossa vida ideológica.

Retendo o argumento principal e suas implicações ulteriores, percebemos que "As ideias fora do lugar" estabelece consideráveis relações com o ensaio "O entre-lugar do discurso latino-americano", de Silviano Santiago. Publicado dois anos antes, em 1971, e tendo como foco uma reflexão sobre a América Latina, o texto de Santiago tem início com a menção a uma história antiga citada por Montaigne, que dá notícias do confronto entre soldados gregos, comandados pelo rei Pirro, e soldados romanos. À superioridade econômica grega deveria corresponder, segundo o rei Pirro, a superioridade militar. No entanto, tal expectativa é quebrada quando, diante dos soldados romanos, o rei reconhece a organização exemplar dos adversários em relação à precária estrutura de suas tropas. A história trata e anuncia o

José Miguel. Veneno Remédio: o Futebol e o Brasil. São Paulo: Companhia das Letras, 2008. Para Schwarz o que não pode ser integralmente racionalizado é o "elemento de arbítrio, o jogo fluido de estima e autoestima a que o favor submete o interesse material". SCHWARZ, Roberto. "As ideias fora do lugar", Ao vencedor as batatas; p.17.

8 Idem, ibidem; p. 21.

9 Esse sentimento de desajuste e falsidade, de acordo com o crítico, ganha ênfase quando confrontado com a ideologia da independência nacional.

10 SCHWARZ, Roberto. op. cit; p. 26

RASILIANA- Journal for Brazilian Studies. Vol. 6, n.1 (December 2017). ISSN 2245-4373. 
assunto mote do ensaio:

O desequilíbrio instaurado pelos soldados gregos, anterior ao conflito armado e, entre os superiores, causa de orgulho e presunção, é antes de tudo propiciado pela defasagem econômica que governa as relações entre as duas nações. Mas no momento mesmo em que se abandona o domínio restrito do colonialismo econômico, compreendemos que muitas vezes é necessário inverter os valores dos grupos em oposição, e talvez questionar o próprio conceito de superioridade. ${ }^{11}$

Com preocupações não tão distantes daquelas do ensaio de Schwarz, Santiago dá início a uma reflexão acerca de uma possível inversão de valores na relação entre o colonialista e o colonizado. Em outros termos, com as devidas atualizações e mediações da historieta narrada, o crítico especula as possibilidades de que países periféricos, ex-colonizados, possam, através da literatura e de outros objetos da cultura, contestar, se proteger e fazer frente ao lugar hegemônico da ex-metrópole, detentora, sobretudo, de poder econômico.

O ponto chave para o início da argumentação de Santiago é, no entanto, não o pósindependência, mas sim a colonização, de acordo com ele, indispensável para que se compreenda nossas dinâmicas socioculturais. Este seria o episódio em que a população indígena, além de parcialmente dizimada, teria perdido, a uma só vez, dois dos principais elementos de uma cultura, a saber: sua língua e seu sistema sagrado. O lastro desse processo teria se estendido até o século XX, quando, mesmo no contexto de nações independentes, um neocolonialismo passou a ser responsável por uma nova etapa de "duplicação" da Europa, quer dizer, pela exportação e instalação em outros países de modas e valores dos países dominantes.

A América Latina teria se transformado em "simulacro que se quer mais e mais semelhante ao original, quando sua originalidade não se encontra na cópia do modelo original, mas na sua origem, apagada completamente pelos conquistadores" ${ }^{12}$ Para Santiago nossa originalidade permanece como lacuna, esquecimento, um vazio suplementar às nossas

11 SANTIAGO, Silviano. "O entre-lugar do discurso latino Latino-Americano". In: Uma literatura nos trópicos. São Paulo: Editora Perspectiva, 1978; p. 12.

12 Idem, ibidem; p.16.

RASILIANA- Journal for Brazilian Studies. Vol. 6, n.1 (December 2017). ISSN 2245-4373. 
produções culturais. ${ }^{13}$ Diferentemente, porém, da colonização primeira que tinha como princípio a unidade - um só Deus, uma só língua - o neocolonialismo, no novo contexto da América independente, teria sido marcado pela mescla de elementos europeus e autóctones, conferindo força e existência à figura do mestiço e do híbrido. Se o preço do colonialismo foi o apagamento de nossa origem, o neocolonialismo teria aberto margens para uma transfiguração ativa dos elementos europeus. Esta nova dinâmica de colonização permitiu, de acordo com o crítico, que o pensamento selvagem se infiltrasse no pensamento do colonizador, destruindo seus conceitos de unidade e pureza e criando condições de possibilidade da descolonização. ${ }^{14}$

Em decorrência disso, perante a situação em que a América Latina não pode fechar as portas aos estrangeiros e tampouco voltar à sua condição de "paraíso" - "isolado e inocente" -, os pares "assimilação e agressividade" e "aprendizagem e reação" deveriam fundamentar o modus operandi de nossa dinâmica sociocultural. De acordo com Santiago, portanto, é a marca da diferença, engendrada por meio do "movimento de desvio da norma, ativo e destruidor" que garante para a América Latina um lugar assegurado na história ocidental. Sem esse sinal de deslocamento na apreensão dos valores e produtos europeus, nós, enquanto cópia, seríamos imperceptíveis; um silêncio diante do velho continente. Nesse sentido, o crítico afirma que qualquer ação aqui realizada é reação: "Falar, escrever, significa: falar contra, escrever contra" ${ }^{15}$

Essa exposição é o pressuposto da ideia de "fazer literário" para Santiago e, por conseguinte, do modo como a atividade da crítica literária é entendida por ele. Utilizando-se do conceito de escritura e da oposição formulada por Barthes entre os textos legíveis e os escrevíveis, o crítico define a atuação do escritor latino americano como uma escritura a partir de outra escritura. Ao entrar em contato com um texto "que pode incitá-los ao trabalho, servir-lhes de modelo na organização da sua própria escritura" (esse seria o texto escrevível), os escritores acionariam uma estratégia de produção em que:

13 Ainda que Santiago esteja se referindo à América Latina em termos gerais, sabemos que tal afirmação se aplica satisfatoriamente ao Brasil (e isso, inclusive, corrobora a comparação com Schwarz que estamos propondo), onde, ainda que (re)exista, a cultura e presença indígena (bem como a negra) é constantemente subtraída das diversas esferas da vida social. Porém, em relação a outros países, como a Bolívia e o Peru, a afirmação careceria de ser mais matizada, já que o elemento indígena, nesses países, assim como as latentes crises decorrentes dele (inclusive linguísticas), sobrevivem com outra notoriedade.

14 SANTIAGO, Silviano, op.cit; p.18.

15 Idem, ibidem; p. 19.

RASILIANA- Journal for Brazilian Studies. Vol. 6, n.1 (December 2017). ISSN 2245-4373. 
O texto segundo se organiza a partir de uma meditação silenciosa e traiçoeira sobre o primeiro texto, e o leitor, transformado em autor, tenta surpreender o modelo original nas suas limitações, nas suas fraquezas, nas suas lacunas, segundo sua própria direção ideológica, sua visão do tema apresentado de início pelo original. ${ }^{16}$

Assim, o excerto deixa-nos perceber que, para Santiago, a cultura e literatura brasileira são pensadas como suplementos da cultura e da literatura europeia e norte americana e viceversa. Ou seja, tais instâncias devem ser concebidas de forma relacional enquanto elementos que permitem a totalização de uma estrutura e são, ao mesmo tempo, um excesso em relação a ela, o que revela certa fragilidade da estrutura enquanto totalidade. Em outras palavras, o suplemento - a literatura ou crítica brasileira, periférica, por exemplo - deve ser acrescentado para que a origem - nesse caso, a literatura ou crítica europeia, hegemônica - legitime-se enquanto tal e simultaneamente, nesse gesto, aponta esta última como insuficiente e revela naquela a lacuna inerente à sua existência. ${ }^{17}$

Sendo assim, no que se refere à crítica literária e cultural, a problemática apresentada até então, em "O entre -lugar do discurso latino-americano", passa pelo fato de a tradição literária dos países periféricos ter cristalizado uma atitude de conferir valor a um objeto pelo que ele possui de correspondência com um equivalente europeu, ou seja, de enfatizar os aspectos de continuidade, e não as diferenças, entre a produção europeia e a latino-

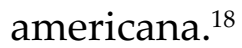

Santiago afirma que, no âmbito da literatura, essa atitude da crítica nacional brasileira explicitaria a introjeção, grave, do olhar neocolonialista nos sujeitos locais que conferem mais valor ao que figura como modelo do que ao resultado, ou ao próprio processo de tradução desse referencial:

16 Idem, ibidem; p. 22.

17 Apesar de ser distinto, o conceito de "suplementariedade", imbricado intimamente na ideia de real desconstrucionista, apresenta um momento de similitude com o conceito de "dialética". A dialética evidencia que no interior de um conceito já há algo que motiva sua superação e que ao negá-lo está também afirmando-o. Tal qual formulada por Hegel, reelaborada por Marx e mobilizada por Schwarz, ela é decisiva para o entendimento do real desde uma crítica materialista.

18 Essa crítica, a nosso ver, não se dirige, nem se aplica diretamente à abordagem schwarziana. Pelo contrário, Schwarz enuncia, em sua leitura de Oswald de Andrade, contra que tipo de leitura a sua vai se colocar, a saber, justamente contra as leituras que buscam uma relação de identidade entre "as soluções oswaldianas e as inovações hoje clássicas das vanguardas internacionais" SCHWARZ, Roberto. "A carroça, o Bonde e o Poeta Modernista". In: Que horas são? São Paulo: Companhia das Letras, 1988; p. 14. 
Tal tipo de discurso crítico apenas assinala a indigência de uma arte já pobre por causa das condições econômicas em que pode sobreviver, apenas sublinha a falta de imaginação de artistas que são obrigados, por falta de uma tradição autóctone, a se apropriar de modelos colocados em circulação pela metrópole. Tal discurso crítico ridiculariza a busca dom-quixotesca dos artistas latino-americanos, quando acentuam por ricochete a beleza, o poder e a glória das obras criadas no meio da sociedade colonialista ou neocolonialista. Tal discurso reduz a criação dos artistas latino-americanos à condição de obra parasita, uma obra que se nutre de uma outra sem nunca lhe acrescentar algo de próprio; uma obra cuja vida é limitada e precária, aprisionada que se encontra pelo brilho e pelo prestígio da fonte, do chefeescola. ${ }^{19}$

O olhar que busca as influências, posto que aprisionado ao modelo europeu, nessa direção, seria nocivo aos interesses da ex-colônia. Para Santiago, esse quadro somente pode ser combatido mediante a adoção da diferença como valor crítico. Essa adoção implica o reconhecimento de que a crença na "liberdade total de criação" - enquanto elemento presente no imaginário do escritor europeu e suprimido das possibilidades criativas do periférico - é "o elemento que estabelece a identidade e a diferença na cultura neocolonialista ocidental". ${ }^{20}$ Esse seria, portanto, o ponto de partida conceitual para uma crítica que pretenda debruçar-se sobre a produção latino-americana.

É possível delinear as "respostas" que são oferecidas por Schwarz - desde uma perspectiva, porém, que parte especificamente do contexto brasileiro ${ }^{21}$ - a essas mesmas questões. Em "As ideias fora do lugar" vemos que um provável movimento de inversão de valores, na relação entre as nações hegemônicas e o Brasil, dar-se-ia na superação que resulta do gesto de enquadrar o desajuste interno (ligado à estrutura material e histórica do país) e, ao mesmo tempo, a necessidade dele imposta pela ordem transnacional. Nas palavras do crítico, se esse movimento for conduzido de maneira convincente (o que é desejável), ele terá

19 SANTIAGO, Silviano. "O entre-lugar do discurso latino-americano", Uma literatura nos trópicos; p. 20.

20 Idem, ibidem; p. 26.

21 Sob a luz, não nos esqueçamos, da obra de Machado de Assis, da qual inclusive deriva a análise que teria possibilitado o desenvolvimento das reflexões presentes no ensaio em questão.

RASILIANA- Journal for Brazilian Studies. Vol. 6, n.1 (December 2017). ISSN 2245-4373. 
o mérito de "superar o fosso entre a singularidade nacional e o rumo geral do presente, introduzindo a crítica nos dois termos". ${ }^{22}$

No entanto, segundo Schwarz, esse procedimento - dialético - nada teria de natural ou espontâneo. Pelo contrário, o "desvio" da norma europeia longe de ser somente uma opção ativa - como o ensaio de Santiago, às vezes, parece sugerir - é determinado pelas condições materiais; não é uma escolha, é uma fatalidade que, como tal, somente adquire valor crítico quando elaborada de modos significativos..$^{23}$ Tendo como pressuposto, filtrado notoriamente pelas ideias luckacsianas e adornianas, a concepção que postula a existência de uma homologia estrutural entre a realidade e as obras artísticas, Schwarz apreende tais obras enquanto objetos relativamente autônomos detentores da capacidade de configurar e transfigurar esteticamente uma determinada realidade socioeconômica, objetos cuja forma, além de revelar algo sobre essa realidade, já é por si um elemento social e antagônico nela.. ${ }^{24}$

Nessa direção, Schwarz também explicita sua concepção da literatura, no caso, como instrumento de crítica e oposição ao sistema capitalista:

Ao longo de sua reprodução social, incansavelmente o Brasil, põe e repõe ideias europeias, sempre em sentido impróprio. É nessa qualidade que elas serão matéria e problema para a literatura. O escritor pode não saber disso, nem precisa para usá-las. Mas só alcança uma ressonância profunda e afinada caso lhes sinta, registre e desdobre - ou evite - o descentramento e a desafinação. Se há um número indefinido de maneiras de fazê-lo, são

22 SCHWARZ, ROBERTO. "Por que as ideias fora de lugar?”. In: Martinha versus Lucrécia: ensaios e entrevistas. São Paulo: Companhia das letras, 2012; p. 169.

23 Sobre isso Schwarz escreve: "São relações que nada têm de automático, e veremos no detalhe quanto custou, entre nós acertá-las para o romance. "As ideias fora do lugar", Ao vencedor as batatas; p. 31.

24 Diante da pergunta “(...) Você se sente mais próximo de Adorno, Benjamin, e dos frankfurtianos em geral, do que de Luckács?", Schwarz responde: "Não tenha dúvida. No entanto, devo muito a Luckács: devo a ele meu esquema de romance europeu (...) Como meu interesse era examinar essas questões [os desvios brasileiros dos modelos europeus], os estudos de Luckács sobre o romance entraram de modo substancial, ainda que negativo, em meu trabalho. Mas voltando à sua questão, agora eu prefiro buscar alguma complementaridade entre Luckács, Benjamin e Adorno a descartar um ou dois deles (...) A meu ver a descrição adorniana da sociedade moderna é mais esclarecedora que a de Luckács, embora aparentemente menos política (...) O argumento pode parecer salomônico, mas é verdade que cada um deles tinha um enfoque diferente. Um se volta para o desenvolvimento das forças produtivas, outro para a alienação, e o terceiro para a luta de classes. Os três aspectos ainda existem, todos mudaram tremendamente e não me parece produtivo escolher exclusivamente um lado".Schwarz, Roberto. Entrevista. Literatura e sociedade/Departamento de teoria literária e literatura comparada/ Faculdade de Filosofia Letras e Ciências Humanas/Universidade de São de Paulo-(2002). São Paulo: USP/FFLCH/DTLLC, 2002; p. 33. 
palpáveis e definíveis as contravenções. ${ }^{25}$

(...) a matéria do artista mostra assim não ser informe: é historicamente formada, e registra de algum modo o processo social a que deve sua existência. Ao formá-la, por sua vez, o escritor sobrepõe uma forma a outra forma, e é da felicidade desta operação, desta relação com a matéria préformada - em que dormita a História - que vão depender profundidade, força e complexidade dos resultados. ${ }^{26}$

Nota-se um paralelismo e ao mesmo tempo uma tensão com as proposições de Santiago. Fica claro que a relação entre a valorização da diferença nacional e a adoção dos paradigmas teóricos e estéticos europeus aparece como preocupação imperativa de ambos os críticos, mas essa reflexão ganha diferentes tratamentos em seus ensaios. A ideia do fazer artístico como um gesto de sobreposição de textos reaparece aqui; no entanto, a trama conceitual que a envolve é muito distinta daquela utilizada por Santiago. Verificamos, de imediato, que a compreensão acerca do que seria a originalidade do país, em Schwarz, é outra. O traço que nos particularizaria no contexto global, não seria apenas a lacuna de nossa origem, mas, sim, os sucessivos gestos, propiciados pela lógica do favor, de apaziguamento dos antagonismos, que, como vimos, precisariam ser flagrados e registrados, pela literatura e pela teoria literária, de modo crítico. Como consequência de certa "neutralização" das oposições irredutíveis, no plano da cultura e do pensamento, nossa originalidade seria, assim, a falta de originalidade e, portanto, a permanente prática da cópia. ${ }^{27}$

Logo, em correspondência direta com o objeto artístico, caberia igualmente à crítica, desde outro lugar e fazendo uso de outra forma (também historicamente estruturada), "registrar" e "desdobrar" a complexidade do desajuste transfigurado na forma estética. Seria este o procedimento utilizado, por exemplo, nas leituras que Schwarz faz da obra machadiana:

Em vez de "panorama" e da ideia correlata de impregnação pelo ambiente, sempre sugestiva e verdadeira, mas sempre vaga e externa, tentei uma

25 Idem, "As ideias fora do lugar", Ao vencedor as batatas; p. 29

26 Idem,ibidem;p. 31.

27 O ensaio "Nacional por Subtração" desenvolve detidamente esse argumento.

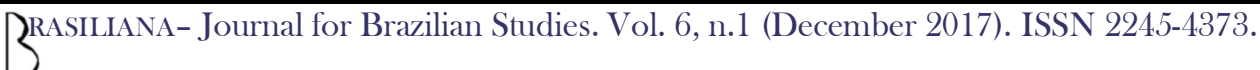


solução diferente: especificar um mecanismo social, na forma em que ele se torna elemento interno e ativo da cultura; uma dificuldade inescapável (...) Pela ordem, procurei ver na gravitação das ideias um movimento que nos singularizava. Partimos da observação comum, quase uma sensação, de que no Brasil as ideias estavam fora de centro, em relação ao seu uso europeu. E apresentamos uma explicação histórica para esse deslocamento (...) Em suma, para analisar uma originalidade nacional, sensível no dia-a-dia, fomos levados a refletir sobre o processo da colonização em seu conjunto, que é internacional. (...) Noutras palavras, definimos um campo vasto e heterogêneo, mas estruturado, que é resultado histórico, e pode ser origem artística. $^{28}$ (grifo do autor)

Fica explícito, desse modo, seu método de análise e seu critério de valoração estética das obras literárias, mas também, como podemos perceber no cotejamento de outros ensaios do autor, da cultura brasileira em geral. A busca da singularidade nacional passa obrigatoriamente pela apreensão das constrições do capital, que determinam relações de produção desiguais e o lugar subordinado do nosso país. Essa tese poderia ser alinhada à crítica que Santiago dirige ao olhar que valora e preocupa-se com o estabelecimento das relações de continuidade e influência da produção latino-americana para com a europeia e estadunidense. Porém, ao invés de deter-se nesse gesto da crítica (que pressupõe o questionamento de uma origem), a proposição de Schwarz acentua o problema da formação do pensamento nacional e fixa claramente a necessidade de criação de uma tradição própria.

\section{Pressupostos e reverberações do diálogo traçado}

Essa estrutura argumentativa de Schwarz é mais desenvolvida no célebre texto "Nacional por subtração", no qual ele revela a noção de cópia cultural como ideologia à medida que pressupõe a possibilidade de que a imitação seja evitada, mas não sem antes reconhecer a "verdade relativa" do problema, do "esforço de atualização e desprovincianização em nossa universidade" em que "é fácil observar que só raramente a passagem de uma escola a outra corresponde, como seria de esperar, ao esgotamento de um projeto; no geral ela se deve ao

28 SCHWARZ, Roberto. "As ideias fora do lugar”, Ao vencedor as batatas; p. 29.

RASILIANA- Journal for Brazilian Studies. Vol. 6, n.1 (December 2017). ISSN 2245-4373. 
prestígio americano ou europeu da doutrina seguinte". ${ }^{29} \mathrm{Ou}$ seja, o problema estaria na adoção apressada e descontínua de modelos de leitura e valores estrangeiros em detrimento da constituição de uma tradição de pensamento nacional.

Nas palavras de Schwarz, são poucos - entre eles Antonio Candido - os que conseguem dar continuidade ao trabalho dos seus predecessores de maneira crítica e dinâmica. Desse modo, ele afirma, ainda, o retrocesso que pode significar descartar os estudos ligados às problemáticas nacionais, já desenvolvidos pela crítica local, em prol de novas teorias. A seu ver, a crítica brasileira atingiu um patamar "altamente sofisticado" de análise - iniciado por Antonio Candido em seus ensaios "De Cortiço a Cortiço" e "Dialética da Malandragem"- no qual as categorias de raça e sexualidade, por exemplo, foram construídas e inseridas "dentro de uma terminologia abstrata, dentro de uma formulação desligada de processos históricos particulares e de uma tomada de consciência histórica, que tem a história nacional atrás" ${ }^{30}$

Na construção de sua tese, Schwarz conta com o respaldo de um discurso de interpretação da realidade brasileira e mesmo que não afirme isso, seus argumentos deixam entrever que dentro da linha evolutiva que ele define como tradição do pensamento brasileiro, sua própria obra constituiria um ponto de chegada (e a escrita do ensaio “Pressupostos, salvo engano, de 'Dialética da Malandragem'” pode ser lida como a explicitação disso). Nesse sentido, emoldurando a discussão que é desenvolvida pela obra desse crítico, faz-se necessário observar que o definido por Schwarz como crítica brasileira diz respeito a uma das correntes, detentora de grande capital simbólico, existentes no campo crítico brasileiro.

A crítica de Santiago não é realizada a partir desse discurso tradicional de interpretação histórico sociológica brasileira, ainda que dialogue com ele. Dessa maneira, os escritos de Santiago apontam, enquanto realização, a possibilidade de uma crítica nacional desvinculada do materialismo dialético. As formulações desse autor ancoram-se, sobretudo, em postulados da desconstrução e não são poucas as citações, referências e incorporações do pensamento de Jacques Derrida presentes em seus textos. ${ }^{31}$ Esse é um fator que contribui para

29 Idem, "Nacional por Subtração", Que horas são?; p.30.

30 Idem, "Literatura y Valor" In: Leituras do Ciclo [Andrade, Ana Luiza, Camargo, Maria Lucia de Barros e Antelo, Raul (orgs)]. Florianópolis: ABRALIC/Chapecó: Griffos, 1999; p 298.

31 No ensaio "O entre-lugar", além de uma longa citação no início do texto, em certo momento, ao expor a atuação do escritor latino-americano como o trabalho de um tradutor do signo estrangeiro, Santiago menciona Derrida: "Seguimos de perto os ensinamentos de Derrida com relação ao problema da tradução dentro dos pressupostos gramatológicos (....)". SANTIAGO, Silviano. Uma literatura nos trópicos; p. 25. O vínculo entre os dois pensadores é reiterado (nesse e em 
a caracterização de Santiago como não pertencente ao grupo identificado por Schwarz como crítica brasileira.

Em consonância com seus referenciais teóricos, para Santiago, seria através dos textos, entendidos como algo diferente de signos gráficos numa folha de papel, que a relação entre literatura, teoria literária e sociedade deveria ser concebida. A despeito das acusações de esteticismo, essa atenção para com os textos partiria do pressuposto de que não existem eventos fora destes e explicar-se-ia a partir de uma concepção filosófica - a crítica à metafísica da presença - segundo a qual o processo de determinação de sentido de um acontecimento é sempre dado a posteriori, através de uma prática discursiva.

Assim, não há fato que não possa ter seu sentido reescrito, retrabalhado ou mesmo apagado - por isso, inclusive, teríamos responsabilidade infinita pelos enunciados que produzimos ou reinscrevemos no presente. A condição latino-americana descrita em "O entre-lugar", por exemplo, seria produto de diversos textos. A transformação sociopolítica, fundante do materialismo dialético na forma de luta contra o capitalismo, nesta formulação aparece ligada ao "verbo". Desse modo, Santiago concorda com Derrida quando este afirma não ser possível uma transformação social que não passe pela linguagem:

A Desconstrução radical, consequente com relação a ela mesma, não quer permanecer fechada em discursos puramente especulativos, teóricos e acadêmicos, mas pretende ter consequências, mudar as coisas e intervir de modo eficiente e responsável (embora sempre mediado, claro) não apenas na profissão mas naquilo que chamamos a cidade, a pólis e, mais geralmente, o mundo. ${ }^{32}$

A linguagem carregaria em si a necessidade de sua própria crítica, "na ausência de centro ou de origem, tudo se torna discurso - com a condição de nos entendermos sobre esta palavra isto é, sistema no qual o significado central, originário ou transcendental, nunca está absolutamente presente fora de um sistema de diferenças". ${ }^{33}$ Ao questionar um determinado

muitos outros textos da obra de Santiago), sobretudo, através do uso que o crítico faz de uma "metodologia" de análise desenvolvida pelo filósofo.

32 DERRIDA, Jacques. Força de Lei: o fundamento místico da autoridade. MOISÉS, Leyla Perrone [trad]. São Paulo: WMF Martins Fontes, 2007; p.14

33 DERRIDA, Jaques. "A estrutura, o signo e o jogo no discurso das ciências humanas". In: A escritura e a diferença. São Paulo: Perspectiva, 1995; p.232-237.

2RASILIANA- Journal for Brazilian Studies. Vol. 6, n.1 (December 2017). ISSN 2245-4373. 
conceito de estrutura centrada, detentora de uma origem fixa ou de um ponto de presença, Derrida desloca a ideia de centro, definindo-o como algo que pode estar dentro ou fora da estruturalidade da estrutura. Postula, assim, uma ausência de significado transcendental o que permitiria e ampliaria o jogo da significação. Em outras palavras, o fato de a linguagem ser finita e as possibilidades de combinação infinitas tornaria as tentativas de totalização sem sentido, inúteis ou impossíveis.

Essa ausência de origem/centro permite o jogo de significações e é o que constitui a base do conceito derridiano de suplementariedade, utilizado por Santiago. É, portanto, certo essencialismo presente na ação de substituição dos centros e não o questionamento dos mesmos o alvo dessa crítica e o dado objetivo que impede a conclusão rápida de que as proposições apresentadas em "O entre-lugar do discurso latino-americano" apontam para uma simples inversão na relação entre ex-colônia e ex-metrópole.

Por outro lado, a necessidade de não se perder a dimensão da totalidade é imprescindível para Schwarz. Em suas ponderações sobre os aspectos socioculturais e literários do Brasil, ele retoma as noções marxistas, já filtradas, como mencionamos, pelos desdobramentos da escola de Frankfurt. ${ }^{34}$ Em resposta à exigência da diferença como único critério de valor proferida por Santiago, o repertório desse crítico o impele a não apenas registrar a diferença, mas sim explicar o processo, o porquê da diferenciação, e na base dessa explicação está o movimento dialético apreendido a partir das condições locais e, também, de uma tradição de pensamento que tem como referência os estudos de Hegel e de Marx.

Desde a perspectiva schwarziana, então, a potencialidade positiva de reconfiguração da relação ex-colônia e ex-metrópole, ou nação periférica e nação hegemônica, que a crítica de Santiago sugere presente no âmbito cultural e literário, seria compreendida como ingênua ou, mais categoricamente, como ideologia que, centrada somente no discurso, ignora a dimensão material e determinante do sistema capitalista. Para Schwarz, a crítica vinculada ao pósestruturalismo seria "crítica de corte abstrato" que apenas rompe conceitualmente com uma subordinação que é efetiva, sendo portanto uma crítica estéril e impotente. Apesar das correspondências que circunscrevem o modo com que Santiago situa a cultura brasileira como suplemento da cultura ocidental e articula a condição local ao panorama transnacional e o modo dialético com que Schwarz também estabelece relações entre a condição das nações

34 E isso não é um detalhe. A dialética negativa de Adorno guarda grande distância da dialética marxista clássica. Os questionamentos adornianos, inclusive, em muito se aproximam da crítica pós-estruturalista, por exemplo, no que se refere à crítica da subjetividade. No entanto, nesse momento pretendemos enfatizar os aspectos de continuidade entre a leitura de Schwarz e os fundamentos básicos do marxismo. 
periféricas e a lógica transnacional do sistema capitalista, a preocupação do materialismo com a práxis é resgatada e salvaguardada em detrimento das outras formas de teoria.

Claro está que a comparação entre esses dois críticos não é passível de ser sintetizada num binarismo simplista ou, como dizem, num "Fla-Flu". As oposições que as abordagens de Santiago estabelecem com as análises schwarzianas têm implicações significativas que procurei indicar e que pude desdobrar mais detidamente em outros trabalhos. Dentro do escopo que delimita as pretensões deste artigo, cabe, por fim, o registro de que algumas arestas se fazem evidentes e interessam enquanto aspectos férteis para o a reflexão acionada na contraposição dos ensaios analisados.

No caso de Santiago, no ensaio "O entre-lugar" mas também em outros, é notório que a significativa, mas deslocada, importância que o crítico confere às relações econômicas, está subordinada à ideia de independência cultural - bem sintetizada na historieta do combate entre os soldados gregos e romanos. Tal dado permite-nos perguntar: se as relações entre as culturas são mediadas por uma dinâmica distinta das relações econômicas e, nesse caso, as nações periféricas não seriam necessariamente subordinadas aos países desenvolvidos, por que a investida tão grande numa produção que marque distância e se coloque enquanto oposição, resistência, à Europa? Esse esforço já não explicitaria uma subordinação? Será que o lugar que esse crítico defende para a literatura brasileira e, em contingência, para a nossa teoria literária - "Entre o sacrifício e o jogo, entre a prisão e a transgressão, entre a submissão ao código e a agressão, entre a obediência e a rebelião, entre a assimilação e a expressão"35 - é possível de existir?

E em Schwarz, na insistência pelo desajuste, que se formula no reconhecimento da necessidade de algumas incorporações teóricas estrangeiras, mas na simultânea defesa de um repertório e modo de incorporação mais válido e coerente do que outros, pode ser lida uma estratégia de autolegitimação que rasura dados não pertencentes ao seu esquema interpretativo e nessa medida, em última instância, reafirma que a única ideia no lugar é a ideia de que as ideias estão fora de lugar? Haveria, como afirma Elias José Palti, uma função ideológica neste processo, que para instaurar um lugar como verdade reduz ou ignora os argumentos contrários a ele (a ideia do outro é sempre a que está fora de lugar), sem questionar o próprio referencial teórico? Afinal se as ideias liberais do século XIX estavam fora de lugar, o que dizer do marxismo, décadas depois?36

35 SANTIAGO, Silviano. “O entre-lugar”, Uma literatura nos trópicos; p. 28.

36 PALTI, Elias José. “The problem of 'Misplaced Ideas' Revisited: Beyond the 'History of Ideas' In Latin America". 
As investidas presentes nos ensaios de Schwarz e de Santiago tentam não reproduzir um pensamento maniqueísta e, para isso, dão corpo e mobilizam os conceitos de "entre-lugar do discurso" e "ideias fora do lugar". Ambos, como vimos, são conceitos relacionais que apontam para formas de desvio em relação a uma norma pondo em jogo as noções de origem/centro/periferia e modelo/cópia/originalidade. São tentativas de reconhecimento daquilo que é exterior a certa racionalidade moderna e peculiar à cultura e contexto sócio-históricos brasileiros. Há nos dois, portanto, um pendor "nacionalista", que de modo complexo e contraditório passa por uma crítica a certo nacionalismo.

Ainda que recategorize as obras desde sua perspectiva, Santiago não as retira da condição primordial de "literatura brasileira". Nesse gesto, de acordo com Palti, reside um problema, isto é, no processo de desestabilizar a ideia de origem e simultaneamente reivindicar uma originalidade da produção cultural e literária brasileira - ou latinoamericana. ${ }^{37}$ Sendo assim, a leitura crítica de uma escritura, que levasse ao limite a lógica da desconstrução, ao conceber de forma complexa os processos de geração, transmissão, difusão e apropriação das ideias, somente poderia estabelecer comparações a partir da particularidade de cada relação e de cada obra. Isto implicaria a eliminação da noção de marcas que dessem conta de uma produção sob a rubrica de "periférica" ou "brasileira", por exemplo.

Por outro lado, o procedimento conceitual de Shwarz consiste em, num primeiro momento, afirmar a existência de ideias fora de lugar no Brasil como algo inevitável, concluindo então que não existe uma essência ou modo de pensar que nos seja próprio; para, depois, num segundo momento - diante de questões como: então o próprio marxismo está fora de lugar? - apontar como legítimas e ajustadas as ideias que forem (re) formuladas a partir das contradições locais e, nessa direção, ratificando, sim, existirem ideias no lugar que nos distinguem e nos dão algum tipo de originalidade - como exemplo disso estaria a obra literária de Machado de Assis e a própria obra de Schwarz. ${ }^{38}$

Do modo como foi exposto aqui, a cotejamento entre a obras de Roberto Schwarz e Silviano Santiago revela-se, assim, potente para uma reflexão sobre Brasil que ainda tem na obras dos próprios autores combustível mobilizante de análises que se querem mais profundas (considerar a forma como são escritos o ensaio, assim como a escolha por esse

Jounal of the History of Ideas, Vol. 67, N.1, Janeiro 2006, p. 147-179.

37 Idem, ibidem.

38 Idem, p. 147-179.

RASILIANA- Journal for Brazilian Studies. Vol. 6, n.1 (December 2017). ISSN 2245-4373. 
gênero, é etapa fundamental do trabalho analítico). As oposições são sinuosas e exigem da crítica um esforço de matização e apreensão da dinâmica viva desses pensamentos que aqui procuramos sinalizar.

\section{Referências bibliográficas}

CEVASCO, Maria Elisa Burgos Pereira da Silva; OHATA, Milton. (orgs). Um crítico na periferia do capitalismo: reflexões sobre a obra de Roberto Schwarz. São Paulo: Companhia das Letras, 2007.

CUNHA, Eneida Leal (org.). Leituras críticas sobre Silviano Santiago. Belo Horizonte: Editora UFMG, 2008.

DERRIDA, Jacques. Força de Lei: o fundamento místico da autoridade. MOISÉS, Leyla Perrone [trad]. São Paulo: WMF Martins Fontes, 2007.

. "A estrutura, o signo e o jogo no discurso das ciências humanas". In: A escritura e a diferença. São Paulo: Perspectiva, 1995

DURÃO, Fabio Akcelrud. "Marx e seus Espectros: Reconstituindo um Debate". In: Desconstruções e contextos nacionais.[Santos, Alcides Cardoso dos, Durão, Fábio Akcelurd, Silva, Maria das Graças G. Villa da (orgs.)]. Rio de Janeiro: 7 letras, 2006.

LIMA, Luiz Costa. "Concepção de História Literária na "Formação". In: Dentro do texto, dentro da vida: Ensaios sobre Antonio Candido. [D' trincas, Maria Ângela e Scarabotolo, Eloísa Faria (orgs)]. São Paulo: Cia das Letras, 1992.

OLMOS, Ana Cecilia Arias. Revistas Culturales de la transición: prácticas políticas y estrategias de intervención cultural - una lectura comparada de Punto de vista y Novos Estudos Cebrap. São Paulo: FFLCH-USP, 2000.

PALTI, Elias José. “The problem of 'Misplaced Ideas' Revisited: Beyond the 'History of Ideas' In Latin America". Jounal of the History of Ideas, Vol. 67, N.1, Janeiro 2006.

SANTIAGO, Silviano. "O entre-lugar do discurso latino Latino-Americano". In: Uma literatura nos trópicos. São Paulo: Editora Perspectiva, 1978.

. Entrevista para Helena Bomeny e Lúcia Lippi Oliveira. Estudos Históricos, Rio de Janeiro, n. 30, 2002. Disponível em: http://www.cpdoc.fgv.br/revista/arq/336.pdf. Acesso em: 13 dez. 2009. 
. Nas malhas da letra: ensaios. Rio de Janeiro: Rocco, 2002.

. As raízes e o labirinto da América Latina. Rio de Janeiro: Rocco, 2006.

SCHWARZ, Roberto. "A carroça, o Bonde e o Poeta Modernista". In: Que horas são? São Paulo: Companhia das Letras, 1988.

. "As idéias fora do lugar". In: Novos Estudos CEBRAP, n. 3, 1973. A edição que utilizo está no livro: Ao vencedor as batatas: Forma literária e processo social nos inícios do romance brasileiro. São Paulo: Duas Cidades, Ed. 34, 2000.

. "Por que as ideias fora de lugar?". In: Martinha versus Lucrécia: ensaios e entrevistas. São Paulo: Companhia das letras, 2012.

- Entrevista. Literatura e sociedade/Departamento de teoria literária e literatura comparada/ Faculdade de Filosofia Letras e Ciências Humanas/Universidade de São de Paulo-(2002). São Paulo: USP/FFLCH/DTLLC, 2002.

."Literatura y Valor" In: Leituras do Ciclo [Andrade, Ana Luiza, Camargo, Maria Lucia de Barros e Antelo, Raul (orgs)]. Florianópolis: ABRALIC/Chapecó: Griffos, 1999.

WAIZBORT, Leopoldo. A passagem do três ao um. São Paulo: Cosac Naify, 2007.

WISNIK, José Miguel. Veneno Remédio: o Futebol e o Brasil. São Paulo: Companhia das Letras, 2008. 